\title{
Solid Dispersion of Artemether in Fast Disintegrating Tablet to Enhance Dissolution Rate and Oral Bioavailability
}

\author{
Pranita Sunil Kanojiya*, Yogita Manohar Charde, Rita Naresh Wadetwar \\ Department of Pharmaceutical Sciences, Rashtrasant Tukadoji Maharaj Nagpur University, Amravati Road, Nagpur, Maharashtra, \\ INDIA.
}

\begin{abstract}
Objectives: Artemether (ART), an antimalarial drug, have poor solubility and low bioavailability. Therefore, solid dispersion of the drug was formulated using Soluplus (SOL) and was incorporated in the fast disintegrating tablet. Materials and Methods: The solid dispersion (SD) was prepared using the solvent evaporation method using a rotary evaporator. The optimized SD was evaluated and then incorporated into the tablet. Results: Solubility studies revealed that ART SD A3 of ratio 1:3 (ART: SOP) showed a significantly higher solubility and dissolution rate than plain ART. FTIR results indicated that there was no incompatibility between the drug and hydrophilic carrier. The DSC as well as XRD studies indicated the transformation from crystalline state of drug into the amorphous form. SEM studies revealed the deposition of ART on the surface of the hydrophilic carrier. In-vitro antimalarial activity was improved of the ART due to the SD formulation. Fast disintegrating tablet of ART SD A3 was produced by using directly compressible excipients such as Ludiflash and Ludipress. Ludiflash containing tablet showed fast disintegration with higher drug release. The pharmacokinetic study in mice showed increased $\mathrm{C}_{\max }$ and $\mathrm{AUC}_{0-24}$ by 1.88 - and 3.19-fold as compared to those of plain drug. Conclusion: The prepared SDs using SOP provided a platform for increased solubility and also improved the bioavailability of ART with feasibility for tablet formulation.
\end{abstract}

Key words: Artemether, Solid dispersion, Fast disintegrating tablet, Malaria, in-vivo study.

Key message: The Artemether solubility was improved with the Soluplus by preparing solid dispersion and used in fast disintegrating tablets resulting in enhancement of the bioavailability after oral administration.

\section{INTRODUCTION}

Drugs have low bioavailability due to poor aqueous solubility or due to erratic absorption. Due to the solubility issues of drugs, it is estimated that $40 \%$ of the NCE (New chemical entity) are deprived to have the status of the marketed drug though these NCE have promising pharmacodynamic effects. ${ }^{1}$

Malaria is caused due to the parasite of Plasmodium spp. transmitted by mosquitoes' bite to the human and conceived through the blood causing infection. Artemisinin represents a vital class of antimalarial drugs that contains sesquiterpene lactone having a bridge of peroxide. Artemether is one of the potent drug which is quite effective in cases of multidrug-resistant strains of the parasite and thus enlisted in the WHO's list of essential medicines. ${ }^{2}$ The drug shows activity against $P$. falciparum strain of both Chloroquine sensitive and Chloroquineresistant and also active against Plasmodium vivax. The drug breaks the life cycle of the malarial parasite resulting in the inhibition of parasite multiplication. The potential effect of the drug hinders due to the poor
Submission Date: 27-03-2021; Revision Date: 08-07-2021; Accepted Date: 08-10-2021.

DOI: 10.5530/ijper.56.1.18 Correspondence: Miss. Pranita Sunil Kanojiya,

Research Scholar, Department of Pharmaceutical Sciences, Rashtrasant Tukaoji Maharaj, Nagpur University, Amravati Road, Nagpur-440 033, Maharashtra, INDIA. Email - kanojiyaprani06@ gmail.com

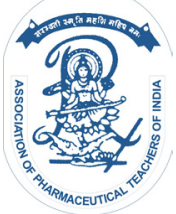

www.ijper.org 
bioavailability resulting from poor aqueous solubility of the drug. ${ }^{3-5}$

The design of an oral formulation containing a poorly soluble drug is very tough and also it should be efficient with safe profile. The main challenge lies in improving the solubility of such drugs and then formulating the same in a suitable dosage form. ${ }^{6,7}$ The widely used method for increasing the aqueous solubility of the poorly soluble drug is formulating the solid dispersion. ${ }^{8}$ The solid dispersion consists of the combination of a poorly soluble drug or active pharmaceutical ingredient with a hydrophilic polymer or carrier either alone or in the combination of two polymers. ${ }^{9,10}$ In the solid dispersion, the active molecule is uniformly dispersed at the molecular level within the carrier matrix and thus improves the solubility, dissolution rate and physical stability. ${ }^{6}$

Soluplus ${ }^{\circledR}$ is a graft co-polymer consisting of polyvinyl caprolactam, polyvinyl acetate and polyethylene glycol. Recently, it is an extensively utilized polymer for the solubility enhancement of poorly soluble drugs for the preparation of the solid dispersions. ${ }^{11-13}$ It is amphiphilic and thus can be effectively used as a solubilizer and as a carrier matrix. Soluplus has shown promising solubilization effect in the case of BCSclass II and IV drugs. The dissolution rate enhancement by formulating the solid dispersion of the drug having poor aqueous solubility using Soluplus can be a beneficial approach. ${ }^{2,14}$ The poor solubility issue of the drug can be resolved by the use of a combination of methods for the increase in oral bioavailability such as preparing the solid dispersion and then adding the same into a fast disintegrating tablet. ${ }^{715}$ The fast disintegrating tablet is a viable option to ascertain the solubility issue. ${ }^{16}$ The use of fast disintegrating tablets for the solubility enhancement can add more benefit for the solid dispersion such as provide faster disintegration and promote quick release of solid dispersion resulting in enhanced dissolution thereby improving the oral bioavailability. ${ }^{17}$ The method for the formulation of the tablets include wet granulation, direct compression, spray drying, freeze-drying and molding. The direct compression method is more economic, industrially feasible and time-saving. ${ }^{18,19}$

For the treatment of malarial infection, the drug must achieve a therapeutic level in the systemic circulation that is only possible when the drug dissolution rate is improved. The present research work can overcome the bioavailability issue of the Artemether by first formulating its solid dispersion using Soluplus and then incorporating the same into a fast disintegrating tablet to achieve the goal by the administration through oral route. To date, there is no literature available for the formulation of the Soluplus -Artemether solid dispersion incorporated in fast disintegrating tablet with the characterization of the formulation for solubility, dissolution, antimalarial activity and bioavailability. The study aimed to formulate and characterize the Artemether-Soluplus solid dispersion prepared by kneading method and solvent evaporation method. The dispersion with high solubility was selected for the direct compression into the fast disintegrating tablet by employing novel excipients and evaluated for the in-vitro studies. The performance of the optimized tablet was investigated by the in-vivo pharmacokinetic study in mice.

\section{MATERIALS AND METHODS}

ART and Myrj 52 were generously gifted by Mangalam Drugs and Organics Ltd., Mumbai and Mohini Organics, Mumbai respectively. Soluplus, Kollidone VA 64, Ludiflash and Ludipress were kind gifts from BASF (Mumbai, India). Plasdone S 630 was a gift sample from Ashland, Hyderabad. Potassium dihydrogen orthophosphate, Sodium Hydroxide were purchased from S. D. Fine Chemicals India. Methanol, Water, and Acetonitrile (HPLC grade) were procured from Merck Specialties Pvt. Ltd., Mumbai. Orthophosphoric acid, Hydrochloric acid, Acetone and Triethylamine were purchased from Loba Chemie, Mumbai. All solvents used for the HPLC system were of HPLC grade. Chloroquine diphosphate and Podophyllotoxin were purchased from Sigma Aldrich (India).

\section{Phase solubility study}

The excess of the ART was added into $10 \mathrm{~mL}$ of $0.1 \mathrm{~N}$ $\mathrm{HCl}+0.5 \%$ Myrj 52 with hydrophilic carriers such as Soluplus, Kollidone VA 64, and Plasdone S 630 (1-10\% $\mathrm{w} / \mathrm{v})$ in a glass vial separately. The sample solutions were sonicated (Ultrasonicator, PCi, Mumbai, India) for $20 \mathrm{~min}$ (at ambient temperature), and kept for shaking for $48 \mathrm{~h}$ at $37 \pm 0.10^{\circ} \mathrm{C}$ at a speed of $75 \mathrm{rpm}$ using orbital shaking thermostable incubator. After 48 $\mathrm{h}$, the solution was centrifuged (REMI model C-24 Plus, REMI Electrotechnik Ltd., Vasai, India) at 10,000 rpm for $20 \mathrm{~min}$ and then filtered utilizing a membrane filter $(0.45 \mu \mathrm{m})$ and analyzed through spectrophotometry (UV-1700, Shimadzu, Japan) at $210 \mathrm{~nm}$ for the drug solubility. ${ }^{11,20}$

\section{Preparation of ART solid dispersion}

\section{Kneading method}

The physical mixture of ART+SOP in various ratios (1:1, 1:2 and 1:3 w/w ratio) was kneaded in a glass 
mortar with the help of a minimum amount of acetone for 15-20 min and the formed thick paste was dried in the oven (Spectra Equipments, Hyderabad) for $24 \mathrm{~h}$ at $45 \pm 1^{\circ} \mathrm{C}$. The dried mass was triturated and passed through the sieve no.50 and stored in a desiccator for further evaluations. ${ }^{21}$

\section{Solvent evaporation method}

The solvent evaporation method was employed for the solid dispersion preparation. The carrier SOP and the drug was accurately weighed (1:1, 1:2 and 1:3 w/w ratio) using a digital weighing balance (Electronic balance, AUX 120, Shimadzu, Japan), this physical mixture was solubilized in a minimum amount of acetone till the mixture dissolved completely. Then the solvent was subjected to evaporation using a rotary vacuum flash evaporator (Jain scientific glassworks, India) at temperature $60^{\circ} \mathrm{C}$ until the dried mass was obtained. This solid residue was pulverized using a porcelain mortar and pestle. The pulverized powder was passed through sieve no.50 and stored in a desiccator for further studies. ${ }^{22}$

\section{Saturation solubility study}

The glass vials were filled with $5 \mathrm{~mL}$ of the dissolution media $(0.1 \mathrm{~N} \mathrm{HCl}+0.5 \%$ Myrj 52$)$ and an excess of the ART SD was added to it. The solution was then kept for shaking for $48 \mathrm{~h}$ in a thermostatic water bath at a temperature of $37 \pm 0.5^{\circ} \mathrm{C}$. The sample solution was removed after $48 \mathrm{~h}$, filtered using membrane filter, diluted suitably and analyzed by UV spectrophotometry at $\lambda_{\text {max }}$ of $210 \mathrm{~nm}^{23}$

\section{Solid-State Characterization FTIR study}

The FTIR analysis was carried out using an FTIR spectrophotometer (Model- IR Affinity 1S, Shimadzu, Japan). The plain ART, SOP, physical mixture of ART and SOP (PM), and optimized SD system were scanned separately for obtaining the spectra. The samples were triturated with $\mathrm{KBr}$ then kept in the sample cell and scanned in the range from 4000 to $800 \mathrm{~cm}^{-1} .^{13}$

\section{DSC studies}

The DSC analysis was performed by using Shimadzu DSC 60 PLUS, Japan. The thermal data obtained were processed using TA60 software. The pure ART, SOP, and optimized SD system were studied. Approximately $3 \mathrm{mg}$ of samples were placed in open platinum crucibles which were heated at a heating rate of $20^{\circ} \mathrm{C} / \mathrm{min}$, to temperatures ranging from $40^{\circ} \mathrm{C}$ to $200^{\circ} \mathrm{C}$ under nitrogen atmosphere $(50 \mathrm{~mL} / \mathrm{min}) .{ }^{24}$

\section{XRD study}

The crystalline nature of ART, PM and optimized SD were evaluated using X-ray powder diffraction studies. The diffraction patterns were obtained on Bruker AXS D8 Advance (Germany) using radiation from $\mathrm{Cu} \mathrm{K \alpha}$ with a voltage and current of $40 \mathrm{kV}$ and $35 \mathrm{~mA}$ respectively with a scanning rate of $2^{\circ}$ per min having angle $2 \theta$ range of $5-60^{\circ} \mathrm{C}$. The diffractograms obtained were then analyzed..$^{24}$

\section{SEM study}

The surface morphology of pure ART, PM and optimized SD were studied by using a scanning electron microscope, (ZEISS EVO 18 Germany). Double-sided carbon tape was affixed on aluminum stubs over which samples were sprinkled. These prepared stubs were coated with gold and placed in the vacuum chamber and magnification was adjusted for an excellent quality image. $^{24}$

\section{Formulation of fast disintegrating tablet using optimized solid dispersion}

Direct compression method was employed for the tablet batches (AFT1 and AFT2) having optimized solid dispersion with excipients; Ludiflash and Ludipress. The two excipients are ready to use excipients having wide applicability. The manual filling of powder mixture (having $80 \mathrm{mg}$ of SD $20 \mathrm{mg}$ of ART) into the die cavity was done. Single punch tablet machine (Chamunda Pharma machinery Pvt. Ltd., India) was used with flat-faced $8 \mathrm{~mm}$ punches for the compression of tablets at the suitable compression pressure to obtain the hardness close to $4 \pm 0.5 \mathrm{~kg}{ }^{19}$

\section{Evaluation of tablets}

\section{Weight variation}

The tablet from the two batches was taken $(n=10)$, weighed individually and the average weight was calculated. The $\%$ weight variation was evaluated by the equation given below:

$$
\text { Weight variation }(\%)=\frac{\begin{array}{l}
\text { Individual tablet weight }- \\
\text { Average tablet weight }
\end{array}}{\text { Average tablet weight }} \times 100
$$

\section{Thickness and diameter}

The thickness and diameter of the tablet(s) $(n=10)$ from each batch were obtained using a vernier caliper (Veego Scientific, India) and the mean value was then calculated. 


\section{Friability}

The previously weighed tablets from two batches $(n=6)$ were placed in the friability chamber (Veego Scientific, India) and subjected for rotation at $25 \mathrm{rpm}$ for $4 \mathrm{~min}$. Then the tablets were removed and again weighed. The friability was taken as the percent of the weight loss during the rotation and was calculated by the equation given below:

$$
\text { Friability }=\frac{\text { Initial weight }- \text { Final weight }}{\text { Initial weight }} \times 100
$$

\section{Drug content}

TheUVmethod was developed fordrug contentestimation with methanol having equation $\mathrm{y}=0.0067 \mathrm{x}+0.0477$ with $\mathrm{R}^{2}=0.9973(20-100 \mu \mathrm{g} / \mathrm{mL})$. A tablet was transferred to a $50 \mathrm{~mL}$ volumetric flask containing $10 \mathrm{~mL}$ of methanol and was diluted to $50 \mathrm{~mL}$ with the same solvent and sonicated (PCi, India) for $30 \mathrm{~min}$. The solution was filtered through a membrane filter and the filtrate was diluted suitably and analyzed by UV spectrophotometry at $\lambda_{\max }$ of $210 \mathrm{~nm}$.

\section{In-vitro disintegration time}

The USP Disintegration apparatus (Campell Electronics, India) was used for the disintegration test. The tablets $(n=6)$ from each batch were placed in the disintegrator cells previously filled with $0.1 \mathrm{~N} \mathrm{HCl}$ equilibrated at $37 \pm 0.5^{\circ} \mathrm{C}$. The sinker was placed after placing the tablet and the time was recorded till the tablet fragments passed through the sinker screen. This point was taken as the disintegration time (in sec). ${ }^{25}$

\section{Screening of antimalarial activity}

The culture of Plasmodium falciparum of Chloroquine sensitive (3D7) strain was used for the in-vitro antimalarial activity. The samples (plain drug ART and the ART SD) were tested against $P$. falciparum 3D7. RPNI medium supplemented with $25 \mathrm{mM}$ HEPES, $0.2 \%$ D-glucose, $0.21 \%$ sodium bicarbonate, and 0.5\% ALBUMAX-II was used for the routine maintenance of the culture. The tested sample stock solutions were prepared using DMSO $(5.0 \mathrm{mM})$ and required dilution was added to the culture medium. Malaria SYBR Green I-based fluorescence (MSF) assay was employed for the estimation of the 50\% Inhibitory concentration $\left(\mathrm{IC}_{50}\right)$ for the samples.

\section{Assay technique}

The highest concentration of $5.0 \mu \mathrm{M}$ was used for the test compounds. Suitable dilutions were added in 96 well-plate and incubated with $1.0 \%$ parasitized cell suspension with $0.8 \%$ parasitemia (Asynchronous culture with $>80 \%$ ring stage). The incubation of the well-plate was carried out at a temperature of $37^{\circ} \mathrm{C}$ in an atmosphere of a mixture of $5 \% \mathrm{CO}_{2}$ and air for 72 h. After the time duration of incubation, lysis buffer $(100 \mu \mathrm{L})$ containing SYBR Green-I was added to the plate and further incubated for $1 \mathrm{~h}$ at $37^{\circ} \mathrm{C}$. Then each well was inspected at $485 \pm 20 \mathrm{~nm}$ for excitation and $530 \pm 20 \mathrm{~nm}$ for emission in relative fluorescence units (RFUs) by using a fluorescence plate reader (FLX800, BIOTEK). The $\mathrm{IC}_{50}$ values were obtained by doseresponse curves by employing Logit regression analysis. The reference drug used was Chloroquine diphosphate.

\section{In-vitro cytotoxic activity}

Monkey kidney fibroblast cells (C1008; Vero cell line) were used for the in-vitro cytotoxicity activity of test samples (Plain ART and optimized SD). The Vero cells were incubated with samples (after suitable dilutions) for $72 \mathrm{~h}$ and MTT reagent was used for the estimation of the cytotoxic activity. The highest concentration $(200 \mu \mathrm{M})$ was utilized for the test samples. The $50 \%$ cytotoxic concentration $\left(\mathrm{CC}_{50}\right)$ was determined using dose-response curves. Podophyllotoxin was used as the reference drug. Selectivity Index (SI) was calculated by using the formula as given below with selection criteria $\mathrm{SI}=>50::^{26,27}$

$$
S I=\frac{\mathrm{CC} 50}{\mathrm{IC} 50}
$$

\section{In-vitro dissolution study}

The dissolution studies were accomplished to ensure the quick release of the drug in the dissolution medium using the USP type I dissolution apparatus (Electrolab, India) at a speed of $100 \mathrm{rpm}$. The ART SD was compared with the plain ART, marketed tablet, AFT1 and AFT2. The in-vitro dissolution was performed in $0.1 \mathrm{~N} \mathrm{HCl}+$ $0.5 \%$ Myrj 52. Sample aliquots of $5 \mathrm{~mL}$ were drawn at different time points up to $120 \mathrm{~min}$. After each withdrawal, an equal volume of dissolution medium was added to each vessel. The samples were filtered and analyzed by UV spectrophotometry at $210 \mathrm{~nm}$ and the percent drug release at each dissolution time point was calculated. For each sample, the test was performed thrice and the results were presented as mean \pm S.D. The graph was plotted as \% cumulative drug release versus time.

\section{Accelerated stability study}

The optimized tablet AFT2 was added inside the capped glass vial wrapped with aluminum foil and placed in 
the humidity chamber (REMI Electrotechnik Ltd., Vasai, India) at a temperature of $40 \pm 2{ }^{\circ} \mathrm{C}$ and humidity condition at $75 \pm 5 \% \mathrm{RH}$ and room temperature. After 3 months of duration, the samples were removed and evaluated for the drug content and $\%$ cumulative drug release.

\section{Pharmacokinetic study}

\section{Animals}

Male Swiss albino mice (weight 30-35 g) were housed in polypropylene cages at a temperature of $25 \pm 2{ }^{\circ} \mathrm{C}$ with a relative humidity of $55 \pm 5 \%$, having free access to diet and water. Before experimentation, the animals were fasted for $8 \mathrm{~h}$ with free access to water. The protocol was approved by the Institutional Animal Ethics Committee (IACE/UDPS/2017/17) and was strictly followed as per the guidelines of the committee.

\section{Administration of dosage form and collection of blood samples}

Animals were divided into two groups of four animals per group $(n=4)$. ART SD tablet suspension was administered to Group 1 animals while Lumerax DT (Ipca, India) tablet suspension was administered to Group 2. All the suspensions were equivalent to ART $(1 \mathrm{mg} / \mathrm{kg}$ body weight) diluted with $0.5 \%$ sodium alginate solution administered orally once to both the groups. The plasma samples were collected at time intervals of $0.25,0.5,1,2,6,12,24,48,72 \mathrm{~h}$ after administration. The sample of blood $(0.25 \mathrm{~mL})$ was taken from the retro-orbital plexus of the mice into the heparinized tubes. The tubes with the blood were centrifuged at $10,000 \mathrm{rpm}$ for $10 \mathrm{~min}$ to extract the plasma and stored at $-20^{\circ} \mathrm{C}$ for further analysis. ${ }^{28}$

\section{HPLC method for drug analysis}

Before the quantification of ART in plasma samples, the calibration curve of plain ART was constructed in the plasma (ART free). The plasma sample $(100 \mu \mathrm{L})$ was mixed with $50 \mu \mathrm{L}$ of internal standard solution (Artesunate $100 \mu \mathrm{g} / \mathrm{mL}$ ) and $50 \mu \mathrm{L}$ of drug solution (methanol containing ART) and vortexed (Impact, Icon Instruments Company, Delhi) for 30s then protein precipitating agent acetonitrile $(500 \mu \mathrm{L})$ was added and vortexed for $1 \mathrm{~min}$. The mixture was centrifuged for $20 \mathrm{~min}$ at $10,000 \mathrm{rpm}$ and the supernatant was filtered and $20 \mu \mathrm{L}$ of the filtrate was injected into the HPLC system..$^{28,29}$ The mobile phase consisted of acetonitrile: methanol $(50: 50 \mathrm{v} / \mathrm{v})$ and $0.01 \mathrm{M}$ ammonium acetate $(\mathrm{pH} 4.5)$ in the ratio of $95: 5(\mathrm{v} / \mathrm{v})$. The system was run in an isocratic mode having $1 \mathrm{~mL} / \mathrm{min}$ of flow rate. The sample was injected with a volume of $20 \mu \mathrm{L}$ and monitored at a wavelength of $216 \mathrm{~nm}$ with a runtime of $2.019 \mathrm{~min}$ for ART. The reconstituted standard solution was applied to the HPLC and chromatograms were obtained. The calibration curve was plotted as peak area ratio versus drug concentration for quantification of ART in the plasma. The calibration graph was linear in the range of $3.4-14.3 \mu \mathrm{g} / \mathrm{mL}$ ( $\mathrm{y}=0.0078 \mathrm{x}-0.029$ with $\mathrm{R} 2=0.999)$ for ART. The sample plasma obtained after administration of ART formulations under the investigation was spiked with the internal standard solution and the same procedurewas applied as performed for the standard sample. This slight modified HPLC method was found to be easy, precise and suitable for the routine analysis of ART in plasma.

\section{Analysis of data for pharmacokinetic study}

The pharmacokinetic data obtained from the study was processed using PK Solver software. The various evaluation parameters $\left(\mathrm{C}_{\max }, \mathrm{T}_{\max }\right.$ and $\left.\mathrm{AUC}_{0-24}\right)$ were evaluated from the plasma concentration-time curve by using non-compartmental analysis. The ratio of the $\mathrm{AUC}_{0-\infty}$ of the optimized tablet to that of the $\mathrm{AUC}_{0-\infty}$ of the marketed tablet known as relative bioavailability was also calculated.

\section{Statistical analysis}

The experiment was carried out thrice and the results were represented as mean \pm S.D.

\section{RESULTS AND DISCUSSION}

\section{Phase solubility study}

The prerequisite for the formulation of the solid dispersion is the selection of the hydrophilic carrier which will increase the aqueous solubility of hydrophobic ART. To ascertain this task, the carrier such as Kollidon VA64, Plasdone S630 and Soluplus were chosen on the basis of earlier literature on solid dispersion. ${ }^{1,12,24}$ The solubility of ART in the presence of the hydrophilic carriers played a key role in the final selection. Thus, the study helped to gain an insight on the influence of the hydrophilic carriers with different concentrations on the drug solubility. Figure 1 represented ART solubility in the aqueous solutions of hydrophilic carriers in various concentrations $(1-10 \% \mathrm{w} / \mathrm{v})$. The experimentally calculated solubility of ART was found to be $0.0017 \mu \mathrm{g} / \mathrm{mL}$ which was concordant with the previous literature. ${ }^{23}$ The ART solubility increased with the increasing concentration of the hydrophilic carriers and after a certain point, there was no further increase in the solubility. The highest solubility was observed for SOP in comparison with the other carriers. The 


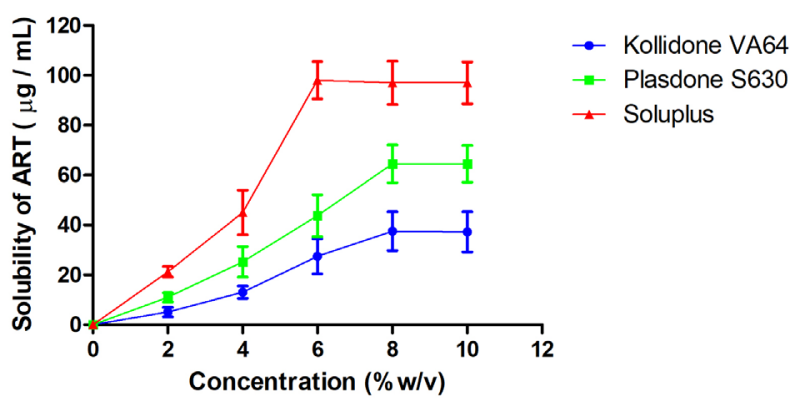

Figure 1: Phase solubility study.

maximum solubility achieved was $93.23 \mu \mathrm{g} / \mathrm{mL}$ in the SOP solution at a concentration of $6 \% \mathrm{w} / \mathrm{v}$. This suggested the higher affinity of SOP for the ART and vice versa which could favor the formation of the dispersion at the molecular level. The SOP (polyethylene glycol-polyvinyl caprolactam acetate grafted copolymer) consists of both lipophilic and hydrophilic moiety. Thus, the amphiphilic nature of SOP leads to higher solubilization of the drug in the aqueous solution. The SOP is nowadays frequently utilized for various poorly water-soluble drugs. ${ }^{13,25}$ The mechanism by which the drug solubility is improved lies in the ability of the SOP to form micelles in the aqueous solution resulting in the higher dissolution. Due to the presence of a large number of electron-withdrawing groups (mainly $\mathrm{O}$ atoms), it was suggested for the higher possibility for the formation of hydrogen bonds between the drug and the SOP.

\section{Selection of method of preparation of solid dispersion}

Based on the phase solubility results, the best hydrophilic carrier nominated was SOP for the final formulation of the solid dispersion of ART. The two methods for the preparation of the solid dispersion such as kneading and solvent evaporation were chosen and the effect of the micellization upon increasing the ratio of the SOP (ART: SOP; 1:1, 1:2 and 1:3) was studied. The kneading method is reported to be very stable and much more convenient for the formulation of the oral dosage form such as tablet. ${ }^{30,31}$ This method is non-hazardous to the environment and also cost-effective. ${ }^{21}$ The solvent evaporation method by using a rotary evaporator leads to the evaporation of the acetone (solvent) in a controlled manner that leads to uniform mixing of the ART and the hydrophilic carrier. This is a simple and single-step process in which the parameters of evaporation (temperature and $\mathrm{rpm}$ ) can be controlled quite easily. This method is thus not very complex. Thus, conversion of thedrug from crystallinestatetoamorphous

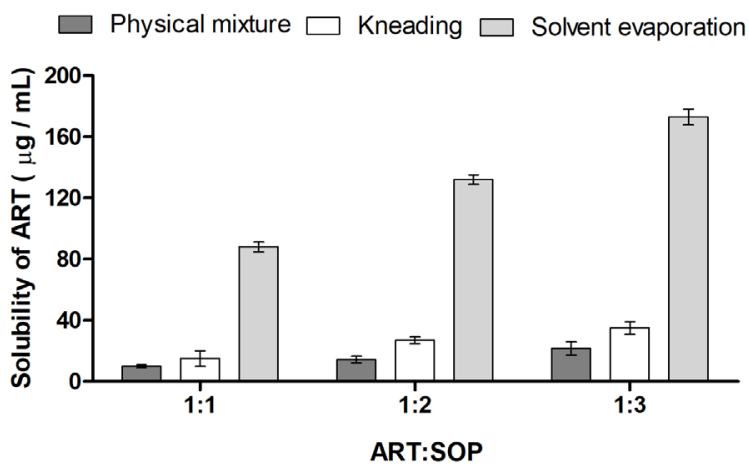

Figure 2: Solubility study of physical mixture of ART and solid dispersion prepared by kneading and solvent evaporation.

state could be expected. The solvent evaporation by rotary evaporator was opted as it prevented ART degradation, caused no threat to the environment with cost-effective benefit. After the consideration of all the above advantages, the rotary evaporation method was thus opted. The evaporation of the solvent was carried out under reduced pressure and high temperature. ${ }^{13}$ The concentration of the hydrophilic carrier that affected the ART solubility is depicted in Figure 2. The SD improved the solubility of ART significantly than observed for the corresponding physical mixture. The higher improvement in the solubility was achieved with the SD obtained from the solvent evaporation method than the kneading method. As the ratio of the hydrophilic carrier was increased, there was an increase in the solubility of the ART. The SOP underwent the micellization process that favors higher solubilization of the ART in the aqueous solution. Higher the micelle formation higher the drug solubility observed when the ratio of SOP was increased in the respective solid dispersions. ${ }^{11}$

\section{Saturation solubility study}

The solubility study was carried out by employing three ratios of physical mixture and prepared SDs (ART: SOL in 1:1, 1:2, 1:3 w/w). The different methods selected were kneading and solvent evaporation for the preparation of the SDs. The physical mixture showed solubility of $9.97 \pm 1.0 \mu \mathrm{g} / \mathrm{mL}, 14.32 \pm 2.2 \mu \mathrm{g} / \mathrm{mL}$ and $21.56 \pm 4.3 \mu \mathrm{g} / \mathrm{mL}$ respectively. The SDs prepared by kneading method had solubility of $15 \pm 5.1 \mu \mathrm{g} / \mathrm{mL}, 27 \pm 2.2 \mu \mathrm{g} / \mathrm{mL}$ and $35 \pm 4.1 \mu \mathrm{g} / \mathrm{mL}$ respectively. The solubility of SDs prepared using solvent evaporation method was $88 \pm 3.3$ $\mu \mathrm{g} / \mathrm{mL}, 132 \pm 3.1 \mu \mathrm{g} / \mathrm{mL}$ and $173 \pm 5.1 \mu \mathrm{g} / \mathrm{mL}$ respectively. The study revealed the increased solubility of ART from the prepared SDs. Both the methods were able to improve the solubility of drug. The higher solubility 
was obtained from the solvent evaporation method as compared to the solubility of the SDs prepared by kneading method. The reason could be effective mixing of the drug and SOP under high temperature and pressure that allowed maximum interaction. In the kneading method, there is only mixing using the solvent without heat application. Thus, the kinetic motion of the molecules of ART and SOP that sets out during heating allowed homogenous fusion which was absent in the kneading method. Hence, solvent evaporation method was finalize for the preparation of SDs and the ratio of $1: 3$ was chosen due to higher solubility value.

\section{Characterization of solid dispersion FTIR study}

FTIR spectra of the characteristic peaks of ART, SOP, PM (ART+SOP) and SD of the optimized batch were studied as shown in Figure 3. FTIR spectrum of ART presented characteristic peak at $\mathrm{OH}$ stretch at $2951.09 \mathrm{~cm}^{-1}$. The $\mathrm{C}-\mathrm{H}$ stretching was observed at $2843.07 \mathrm{~cm}^{-1}$, C-H bending at $1373.32 \mathrm{~cm}^{-1}$, C-O-C stretching at $1136.07 \mathrm{~cm}^{-1}$ and $\mathrm{C}-\mathrm{O}-\mathrm{O}-\mathrm{C}$ bending at $1188.15 \mathrm{~cm}^{-1}$. The $\mathrm{H}-\mathrm{C}=\mathrm{O}$ stretching at $2721.56 \mathrm{~cm}^{-1}$,

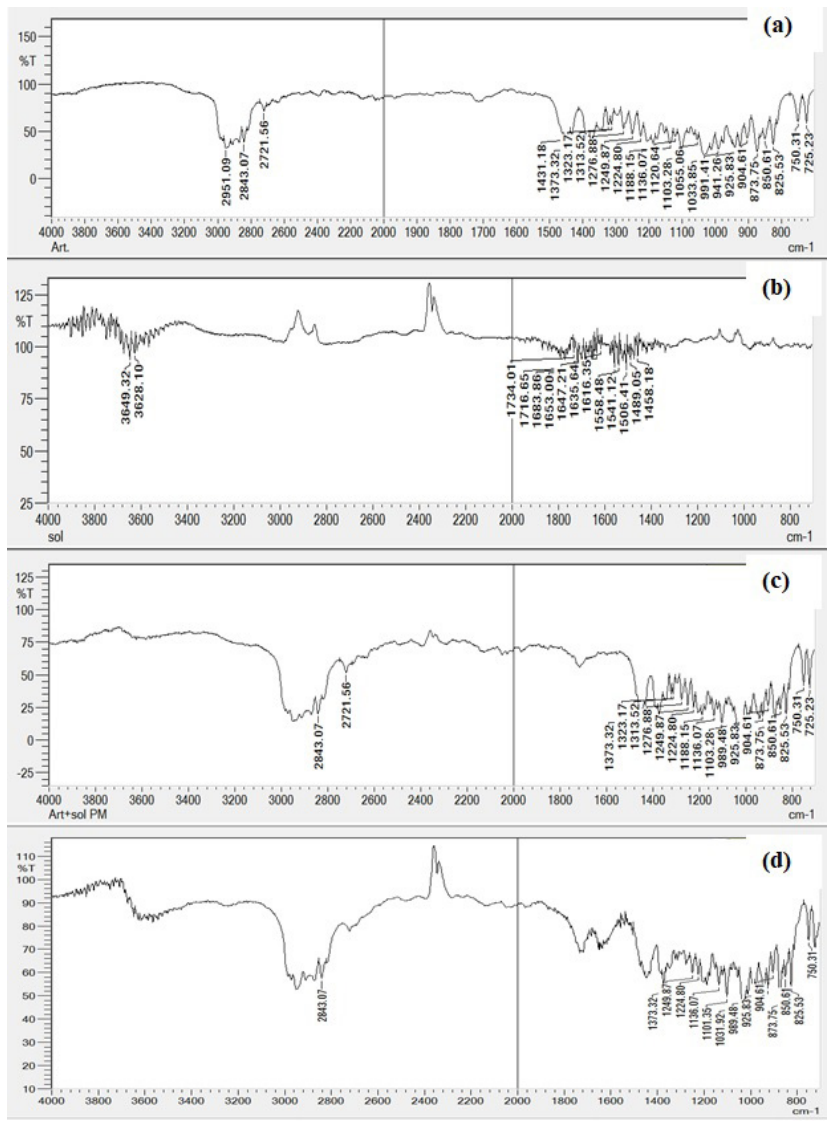

Figure 3: FTIR spectra of (a) ART, (b) SOP, (c) Physical mixture (ART+SOP) and (d) A3 SD. aromatic C-H at $1431.18 \mathrm{~cm}^{-1},-\mathrm{C}-\mathrm{H}$ at $1373.32 \mathrm{~cm}^{-1}$, alcohol C-O stretching at $1055.06 \mathrm{~cm}^{-1}$, ether C-O stretching at $1033.85-1276.88 \mathrm{~cm}^{-1}$. The FTIR spectra of SOP exhibited various peaks for $\mathrm{C}=\mathrm{H}$ aromatic stretching at $1489.05 \mathrm{~cm}^{-1}, \mathrm{C}=\mathrm{O}$ stretching at $1734.01 \mathrm{~cm}^{-1}$ and the free $\mathrm{OH}$ stretching at $3649.32 \mathrm{~cm}^{-1}$. The peaks observed for ART and SOP were concordant with the previous findings. ${ }^{27}$ The spectra of ART+SOP and optimized SD A3 were found to be nearly similar suggesting no incompatibility occurred in the PM as well as in the $\mathrm{SD}$ formulation. The characteristic $\mathrm{OH}$ stretching peak at $2951.09 \mathrm{~cm}^{-1}$ and $\mathrm{H}-\mathrm{C}=\mathrm{O}$ stretching at $2721.56 \mathrm{~cm}^{-1}$ were disappeared in the FTIR spectra of A3 as a result of interaction because the hydrogen bonding operated between ART and SOP. The interaction was observed in the PM and SD system. This interaction between the ART and SOP exhibited formation of molecular dispersion and thus were not affected chemically which means that both the components of the SD system were compatible.

\section{DSC study}

The DSC thermograms of SOP, ART and ART SD A3 were studied which are represented in Figure 4. No endotherm of SOP was observed because of its amorphous nature. Pure ART showed a sharp endothermic peak at $86.52^{\circ} \mathrm{C}$ with an enthalpy change of $44.01 \mathrm{~J} / \mathrm{g}$ and an exothermic peak at $163.59^{\circ} \mathrm{C}$ with
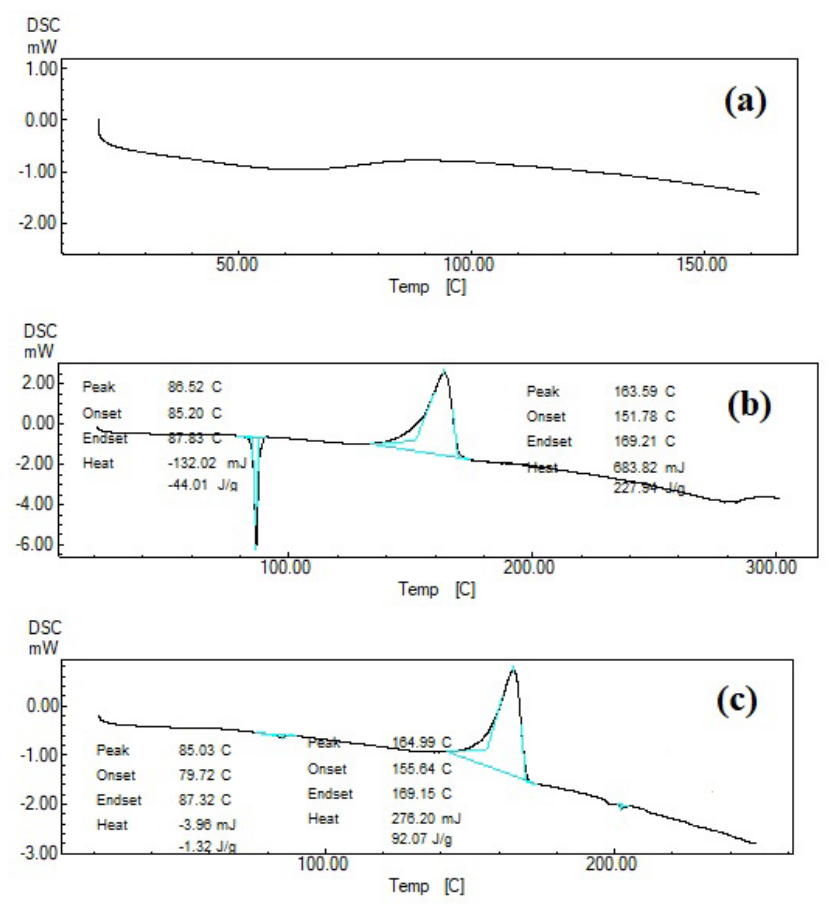

Figure 4: DSC thermogram of (a) SOP, (b) plain ART, and (c) A3 SD. 
an enthalpy of $227.94 \mathrm{~J} / \mathrm{g}$. These results suggested that ART was crystalline and was in line with the previous literature. ${ }^{23}$ In the A3 SD system, the disappearance of the characteristic sharp endothermic peak of ART was observed with melting event of ART at a temperature of $85.03^{\circ} \mathrm{C}$ with enthalpy of $1.32 \mathrm{~J} / \mathrm{g}$. The exothermic peak was observed at a temperature of $164.99^{\circ} \mathrm{C}$ having an enthalpy of $92.07 \mathrm{~J} / \mathrm{g}$. The drop in the enthalpy of the endothermic (from $44.01 \mathrm{~J} / \mathrm{g}$ to $1.32 \mathrm{~J} / \mathrm{g}$ ) and exothermic peaks (from $227.94 \mathrm{~J} / \mathrm{g}$ to $92.07 \mathrm{~J} / \mathrm{g}$ ) of ART suggested that there may be some degree of interaction between ART and SOP in the SD. The thermogram of the SD A3 suggested the formation of solid dispersion with conversion into the amorphous form. These results also suggested reduction in the crystallinity of ART that contributed to the increased drug solubility. Interactions such as hydrogen bonding may be the
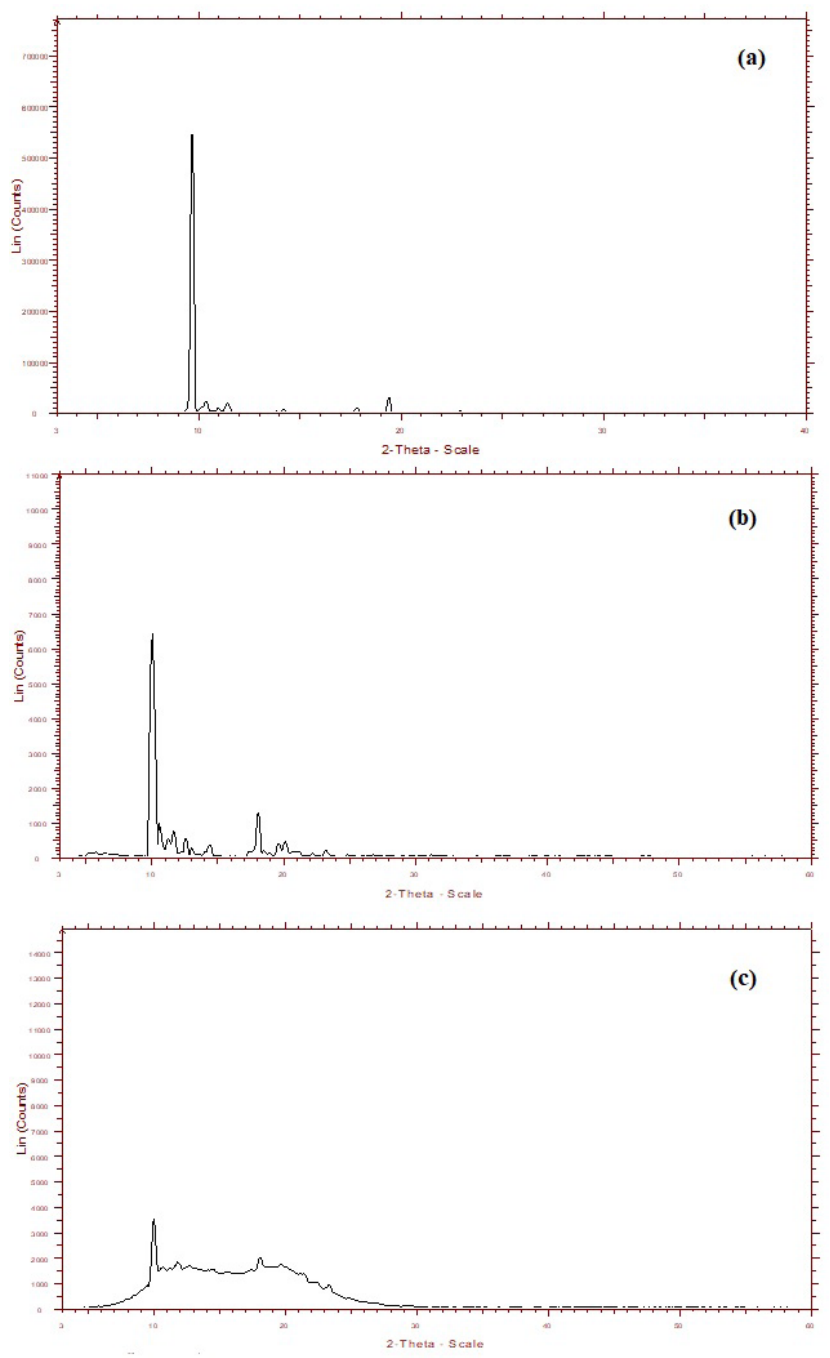

Figure 5: XRD of (a) ART, (b) physical mixture (ART+SOP) and (c) A3 SD. possible reason. These results are in agreement with the FTIR studies.

\section{XRD study}

The X-ray diffractograms of ART, PM and optimized SD are shown in Figure 5, which illustrates the vital modification in the structure of ART crystal after the $\mathrm{SD}$ formation. From the XRD diffraction pattern of pure ART, it was suggested that it is a crystalline compound, showing a very strong diffraction peak at $2 \theta$ of $9.653^{\circ}$ with intensity count $=547410$ Lin (Counts) and other peaks at $2 \theta$ of $10.300^{\circ}, 11.404^{\circ}, 19.395^{\circ}$. PM represented the weak diffraction peak intensity count $=6500 \mathrm{Lin}$ (Counts) with the peak at $2 \theta$ of $9.979^{\circ}$. In the case of ART SD (1:3) diffraction peak was at $2 \theta$ of $9.939^{\circ}$ with intensity count $=3500$ Lin (Counts) can be seen in the diffractogram. The diffractogram of A3 SD depicted low peak intensity with decreased crystallinity. Thus, A3 SD prevented crystallization tendency and kept the dispersion at the molecular level into the matrix of the hydrophilic carrier. The crystalline status of ART changed because of SOP, with most characteristic ART peaks appeared diminished suggested that ART was converted into the amorphous form. The loss of ART crystalline structure occurred due to the interaction between the drug and SOP. It was also confirmed from the A3 diffractogram that ART was uniformly and completely dispersed into the hydrophilic matrix carrier. This data also corresponds with the DSC studies.

\section{SEM study}

SEM photomicrographs of free ART, PM and optimized SD were used for the morphological study. SEM
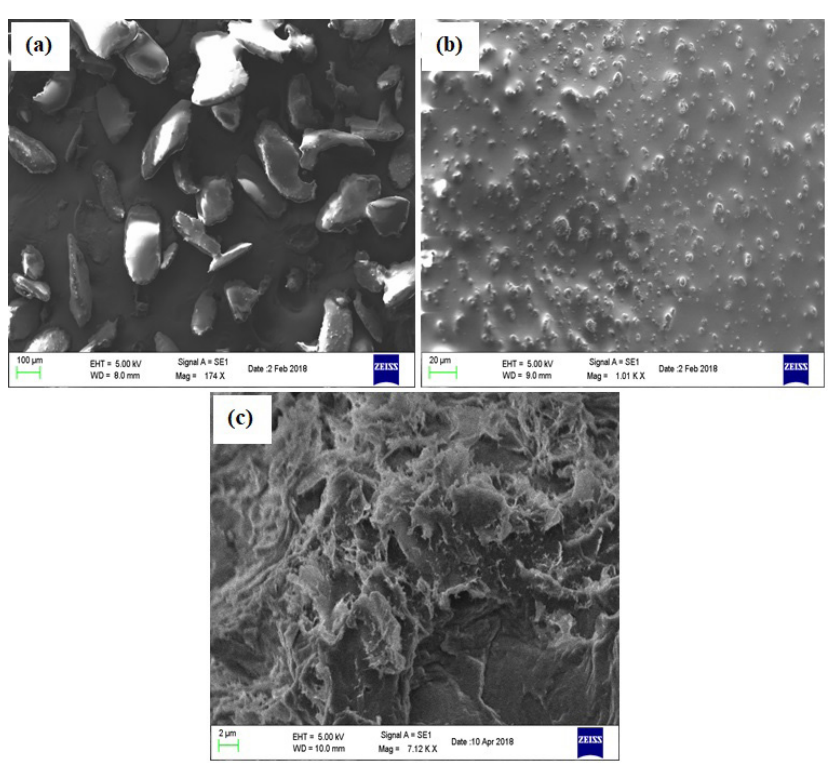

Figure 6: SEM images of (a) ART, (b) physical mixture (ART+ SOP) and (c) ART SD. 
photographs of ART alone showed typical large crystalline blocks having sharp edges and nonuniform particle shapes as shown in Figure 6. SOP showed irregular-shaped spherical particles with rough surfaces in the physical mixture. The prism-shaped ART crystals were absent and thus were different from the pristine drug depicting the formation of the SD A3. The SD A3 appeared to be agglomerated and the fusion of components was observed. The ART and SOP structures were lost during the rotary evaporation. The reason may be that the drug was completely fused with SOP. This inhibited the recrystallization of ART in solid dispersion. Deposition of the ART was observed on SOP in the case of the SD A3. The ART presented amorphous nature having close contact with the hydrophilic carrier and which is critical in enhancing drug solubility and dissolution rate.

\section{Screening of antimalarial activity}

In-vitro antimalarial activity demonstrated a small concentration of SD A3 showed activity against P. falciparum 3D7 having $\mathrm{IC}_{50}$ of $0.059 \mathrm{ng} / \mathrm{mL}$ while for the plain ART, the value was $0.24 \mathrm{ng} / \mathrm{mL}$. Thus it was concluded that SD A3 represented higher activity against malarial parasite than the corresponding plain ART as well as the standard antimalarial drug, Chloroquine $\left(\mathrm{IC}_{50}\right.$ value of $\left.1.73 \mathrm{ng} / \mathrm{mL}\right)$. The formulation of SD with the SOL improved the solubility that aided in the enhanced antimalarial activity and inhibited the parasite. It can thus be concluded that the prepared SD A3 showed higher antimalarial efficacy as compared to plain drug ART and standard drug.

\section{In-vitro cytotoxicity assay}

The in-vitro cytotoxicity study was carried out to check whether the SD would harm the healthy cells of the body or remain neutral. Hence, the Vero cell line was chosen as this cell line is routinely used to carry out the toxicity study. The $\mathrm{CC}_{50}$ value of ART SD was found to be $397.79 \mu \mathrm{g} / \mathrm{mL}$ as compared to ART $(520 \mu \mathrm{g} / \mathrm{mL})$. Cytotoxic activity on Vero cell lines showed a selectivity index of $>50$ for A5 indicating its non-toxicity. It was observed that ART SD showed no toxicity in monkey kidney cells.

\section{Formulation of fast disintegrating tablet using optimized solid dispersion}

The direct compression method for tablet production is one of the widely applied and convenient methods. ${ }^{32-34}$ The process of compression using a directly compressible excipient is quite easy and cost-effective for the industrial application with a minimum number of steps involved in it. The tablet formulations are sturdy because special packaging is not required with ease in modulation for handling. The mechanical characteristics of the tablet such as friability, hardness and disintegration are not affected much and can withstand the external stress in a better fashion. ${ }^{34,35}$ The important aspect that is needed to consider is the right selection of the excipients for the tablet as it can affect the physicochemical characteristics of the final tablet formulation. Thus, tablets were prepared by direct compression (200 mg weight of each tablet) of the selected solid dispersion A3. The investigation was made by studying the effect of two tablet excipients; Ludiflash and Ludipress on the tablet properties. Ludiflash is mainly co-processed mannitol (90\%) with crospovidone and polyvinyl acetate. The characteristic features of Ludiflash are good flowability, taste-masking properties and good compressibility that results in short disintegration time and consequently faster dissolution rate with enhanced palatability with smooth mouth feeling. ${ }^{36}$ Ludipress is free-flowing, white powder of Lactose monohydrate (93\%) with povidone and crospovidone. The characteristic properties are high flowability with excellent blending capacity. ${ }^{37}$

\section{Evaluation of ART SD fast disintegrating tablets}

Tablets were successfully prepared by direct compression using Ludiflash and Ludipress. Table 1 presents the composition and evaluation parameters of the prepared tablets. The tablets had satisfactory organoleptic properties such as pearl white appearance, compact structure and durability for ease in handling.

\begin{tabular}{|c|c|c|c|c|c|c|c|}
\hline \multicolumn{7}{|c|}{ Table 1: Characteristics of the prepared tablets. } \\
\hline $\begin{array}{c}\text { Tablet } \\
\text { code }\end{array}$ & Excipient & $\begin{array}{c}\text { Mean } \\
\text { Diameter } \\
(\mathbf{c m})\end{array}$ & $\begin{array}{c}\text { Mean } \\
\text { Thickness } \\
(\mathbf{c m})\end{array}$ & $\begin{array}{c}\text { Weight } \\
\text { variation (\%) }\end{array}$ & $\begin{array}{c}\text { Drug content } \\
(\%)\end{array}$ & $\begin{array}{c}\text { Friability } \\
\mathbf{( \% )}\end{array}$ & $\begin{array}{c}\text { Disintegration time } \\
(\mathbf{s})\end{array}$ \\
\hline AFT1 & Ludiflash & $0.82 \pm 0.05$ & $0.252 \pm 0.008$ & $0.31 \pm 0.005$ & $98.12 \pm 0.38$ & $0.216 \pm 0.08$ & $93 \pm 12$ \\
\hline AFT2 & Ludipress & $0.83 \pm 0.04$ & $0.253 \pm 0.007$ & $0.47 \pm 0.006$ & $97.93 \pm 0.71$ & $0.241 \pm 0.06$ & $289 \pm 35$ \\
\hline
\end{tabular}


Regarding physical properties, it was observed that there was uniformity in the diameter and thickness of the tablets with very less values of weight variation. The tablets had higher ART content $(>90 \%)$ as obtained in the drug content assay. In the friability test, the tablet batches under the study were compact without the occurrence of any cracking or capping and less than $1 \%$ weight loss was observed (0.321-0.448) which was in line with the reported pharmacopoeial limits. ${ }^{34}$ The AFT1 tablets gave a short disintegration time $(<2 \mathrm{~min})$ compared to the AFT2 tablets ( $>$ $4 \mathrm{~min})$. The reason could be higher porosity and quick penetration of water deep into the tablet due to the presence of mannitol in Ludiflash with no blocking of the pores and quick action of the disintegrant.

\section{In-vitro dissolution study}

The dissolution study was executed for the ART, marketed tablet, A3 and the prepared tablets (AFT1 and AFT2) as shown in Figure 7. The drug release from A3 was $98.25 \%$ and plain ART showed only $57.46 \%$ release at the end of $2 \mathrm{~h}$ which suggested the slower rate of dissolution due to poor aqueous solubility while the SD A3 and the tablets (AFT1 and AFT2) showed improved dissolution rate. The enhanced solubility of ART was observed as a result of the formulation of the solid dispersion employing the hydrophilic carrier i.e., SOP. In the dissolution process of the tablets, SOP played a

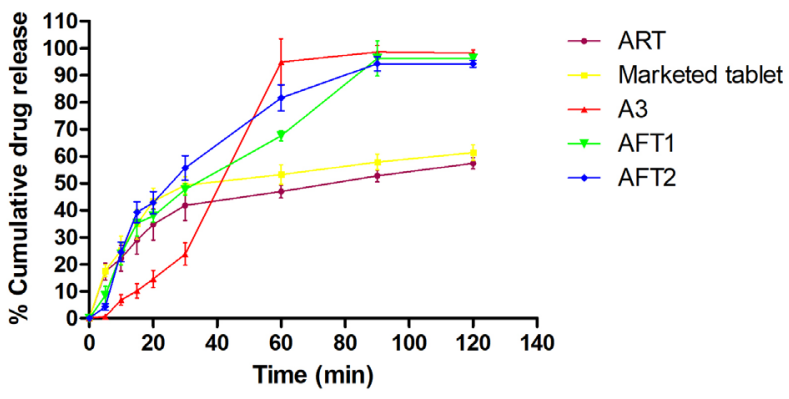

Figure 7: Cumulative drug release of drug. vital role in quickly solubilizing the ART and ensured that a larger volume of the dissolution medium was swapped by the ART. This was possible due to the wetting of ART in the presence of the SOP. During the formation of the SD, the hydrophilic matrix of SOP entraps the ART which leads to the overall coating of the ART uniformly. The ART is crystalline and when the heating and evaporation occurs, there is a breaking of the crystalline lattice of the ART structure forming a disordered random structure imparting amorphous form. Thus, the particle size of the drug gets reduced which provides a larger surface area for the interaction with the dissolution media leading to the higher solubilization followed by dissolution. ${ }^{23-25}$ The transition from the crystalline state to the amorphous state of ART due to the solid dispersion formulation as confirmed from DSC and XRD studies resulted in enhanced dissolution rate due to decreased surface tension between the drug and dissolution media brought about by SOP through the micellar solubilization. The comparison between the AFT1 and AFT2 tablets was performed which showed higher dissolution from AFT1 tablets. The drug release from AFT1 and AFT2 tablets after $2 \mathrm{~h}$ was $96.21 \%$ and $94.26 \%$ respectively. The SD A3 and the tablets were superior in the dissolution rate from the marketed tablet as well as plain ART. The AFT1 and the SD A3 shared an almost similar pattern of dissolution profile. The release kinetic data is presented in Table 2. It was concluded that the plain ART fitted into Higuchi modeling, the SD A3 followed Korsmeyer-Peppas release with $n$ value $>1$ with nonfickian release super case 2 while the marketed tablet also depicted Korsemeyer-Peppas release with $n$ value $<0.45$ with quasi diffusion mechanism. The AFT1 and AFT2 tablets showed the Higuchi release mechanism.

\section{Accelerated stability study}

No significant change in drug content and in-vitro release study was observed in the accelerated stability study as shown in Table 3 and the tablets were stable at

\begin{tabular}{|c|c|c|c|c|c|}
\hline \multirow{2}{*}{ Formulation } & Zero order plot & First order plot & Higuchi plot & \multicolumn{2}{|c|}{ Korsemeyer-Peppas plot } \\
\cline { 3 - 6 } & & & & $\mathbf{R}^{\mathbf{2}}$ & $\mathbf{n}$ \\
\hline Plain ART & 0.7546 & 0.9076 & $\mathbf{0 . 9 6 9 5}$ & 0.9615 & 0.3763 \\
\hline SD A3 & 0.8599 & 0.8654 & 0.8993 & $\mathbf{0 . 9 3 4 8}$ & 1.462 \\
\hline Marketed tablet & 0.6698 & 0.8167 & 0.8579 & $\mathbf{0 . 8 9 6 9}$ & 0.3757 \\
\hline AFT1 & 0.914 & 0.8654 & $\mathbf{0 . 9 6 5 7}$ & 0.9458 & 0.694 \\
\hline AFT2 & 0.8443 & 0.8654 & $\mathbf{0 . 9 4 3 8}$ & 0.8364 & 0.7823 \\
\hline
\end{tabular}




\begin{tabular}{|c|c|c|c|}
\hline \multicolumn{4}{|c|}{ Table 3: Stability study of tablet AFT1. } \\
\hline $\begin{array}{c}\text { Evaluation } \\
\text { parameter }\end{array}$ & $\begin{array}{c}\text { 0 day } \\
\text { at room } \\
\text { temperature }\end{array}$ & $\begin{array}{c}\text { 3 months } \\
\text { at room } \\
\text { temperature }\end{array}$ & $\begin{array}{c}\text { 3 months at } \\
\mathbf{4 0}{ }^{\circ} \mathbf{C ~ 7 5 \%} \\
\text { RH }\end{array}$ \\
\hline $\begin{array}{c}\text { In-vitro } \\
\text { dissolution study }\end{array}$ & $91.26 \pm 2.1 \%$ & $90.98 \pm 1.9 \%$ & $90.96 \pm 2.3 \%$ \\
\hline Drug content \% & $99.12 \pm 2.25 \%$ & $98.95 \pm 2.11 \%$ & $98.92 \pm 1.36 \%$ \\
\hline
\end{tabular}

Each value represented the mean \pm S.D. $(n=3)$

\begin{tabular}{|c|c|c|}
\hline \multicolumn{3}{|c|}{ Table 4: Pharmacokinetic parameters for different } \\
formulations. \\
\hline Parameters & Marketed tablet & AFT1 \\
\hline $\mathrm{C}_{\max }(\mathrm{ng} / \mathrm{mL})$ & $241.87 \pm 42$ & $455.82 \pm 67$ \\
\hline $\mathrm{T}_{\max }(\mathrm{h})$ & $3.205 \pm 0.57$ & $2.9248 \pm 0.19$ \\
\hline $\mathrm{AUC}_{0-24}(\mathrm{~h} . \mathrm{ng} / \mathrm{mL})$ & $921.751 \pm 115$ & $2942.792 \pm 553$ \\
\hline $\begin{array}{c}\text { Relative } \\
\text { bioavailability }\end{array}$ & & 3.188 \\
\hline
\end{tabular}

Each value represented the mean \pm S.D. $(n=3)$

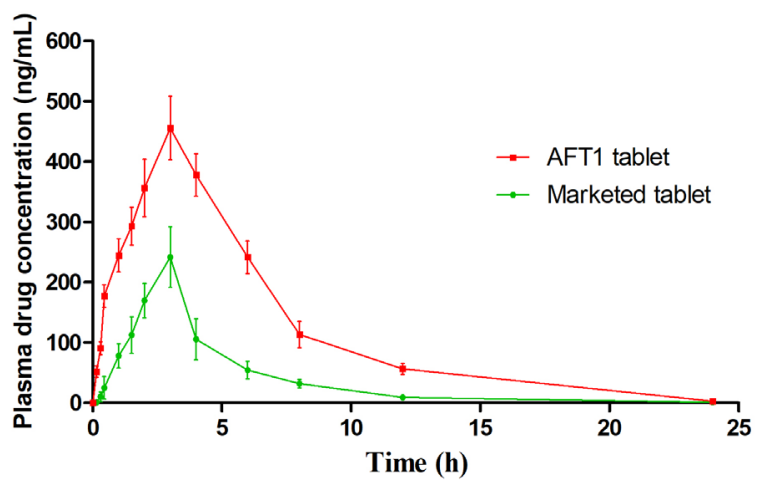

Figure 8: Pharmacokinetic profile of prepared tablet and marketed tablet after oral administration.

both temperatures. Thus, it can be concluded that the SD-based tablets were quite sturdy and can withstand increased temperature also.

\section{Pharmacokinetic study}

The in-vivo study using mice was undertaken to evaluate the parameters such as $\mathrm{AUC}_{0-24}, \mathrm{C}_{\max }$ (observed maximum plasma concentration following drug administration) and $\mathrm{T}_{\max }$ obtained after oral delivery by plotting the plasma-concentration time profile curve. The plasma concentration versus time graph is depicted in Figure 8. The parameters for the pharmacokinetic study are listed in Table 4. The ART SD tablet represented a significant increase in plasma concentration than the marketed tablet. The $\mathrm{AUC}_{0-24}$ and $\mathrm{C}_{\max }$ values of the ART SD tablet were 1.88 times and 3.19 times higher than the marketed tablet respectively. The improved bioavailability can be due to the formation of solid dispersion of ART, as a result, the high plasma level of the drug was achieved quite faster. A slight decrease in the $t_{1 / 2}$ of ART SD tablet was observed. The reason could be the higher and quick dissolution of ART which resulted in spiking drug loading into the systemic circulation. Thus the pharmacokinetic studies showed an improvement in the bioavailability of the drug.

\section{CONCLUSION}

The present work aims to formulate a quick disintegrating tablet of Artemether for the efficient therapy of malaria. The solid dispersion was prepared using Soluplus to improve the solubility of the Artemether by the solvent evaporation method. The A3 (ART: SOP ratio 1:3) showed maximum solubility and also had higher antimalarial efficacy as compared to the plain drug. The optimized solid dispersion was formulated into the fast disintegrating tablet and in-vitro dissolution study exhibited rapid dissolution of the drug. In-vivo pharmacokinetic studies in mice showed significant improvement in bioavailability of the ART. Thus, Artemether solid dispersion in the fast disintegrating tablet may prove to be a promising approach in the effective treatment of malaria.

\section{ACKNOWLEDGEMENT}

The authors would like to thank Mangalam drugs (Mumbai) for the drug sample of Artemether, BASF (Mumbai) for the samples (Soluplus, Ludiflash, Ludipress, Kollidone VA64), Ashland (Hyderabad) for a sample of Plasdone S630 and Mohini organics (Mumbai) for the sample of Myrj 52.

\section{CONFLICT OF INTEREST}

The authors declare no conflict of interest.

\section{ABBREVIATIONS}

ART: Artemether; SOP: Soluplus; PM: Physical mixture; MAR: Marketed tablet; SD: Solid dispersion; DSC: Differential scanning calorimetry; FTIR: Fourier transformed infrared spectroscopy; HPLC: Highperformance liquid chromatography; SEM: Scanning electron microscopy; XRD: X-ray diffraction; DMSO: Dimethyl sulphoxide.

\section{REFERENCES}

1. Pawar JN, Shete RT, Gangurde AB, Moravkar KK, Javeer SD, Jaiswar DR, Amin PD. Development of amorphous dispersions of artemether 
with hydrophilic polymers via spray drying: physicochemical and in silico studies. Asian J Pharm Sci. 2016;11(3):385-95. doi: 10.1016/j. ajps.2015.08.012.

2. Meremikwu M, Alaribe A, Ejemot R, Oyo-Ita A, Ekenjoku J, Nwachukwu C, Ordu D, Ezedinachi E. Artemether-lumefantrine versus artesunate plus amodiaquine for treating uncomplicated childhood malaria in Nigeria: randomized controlled trial. Malar J. 2006;5:43. doi: 10.1186/1475-2875-543, PMID 16704735.

3. Tuteja R. Malaria - An overview. FEBS Journal. 2007;274(18):4670-9. doi: 10.1111/j.1742-4658.2007.05997.x, PMID 17824953.

4. Delves M, Plouffe D, Scheurer C, Meister S, Wittlin S, Winzeler EA, Sinden RE, Leroy $D$. The activities of current antimalarial drugs on the life cycle stages of plasmodium: A comparative study with human and rodent parasites. PLOS Med. 2012;9(2):e1001169. doi: 10.1371/journal.pmed.1001169, PMID 22363211.

5. Pawar JN, Desai HR, Moravkar KK, Khanna DK, Amin PD. Exploring the potential of porous silicas as a carrier system for dissolution rate enhancement of artemether. Asian J Pharm Sci. 2016;11(6):760-70. doi: 10.1016/j.ajps.2016.06.002.

6. Hassouna F, Abo El Dahab M, Fulem M, De Lima Haiek A, Laachachi A, Kopecký D, Šoóš M. Multi-scale analysis of amorphous solid dispersions prepared by freeze drying of ibuprofen loaded acrylic polymer nanoparticles. J Drug Deliv Sci Technol. 2019;53(July). doi: 10.1016/j.jddst.2019.101182, PMID 101182.

7. Brough C, Williams RO. Amorphous solid dispersions and nanocrystal technologies for poorly water-soluble drug delivery. Int J Pharm. 2013;453(1):157-66. doi: 10.1016/j.jpharm.2013.05.061, PMID 23751341.

8. Van Den Mooter G. The use of amorphous solid dispersions: A formulation strategy to overcome poor solubility and dissolution rate. Drug Discov Today Technol. 2012;9(2):e79-85. doi: 10.1016/j.ddtec.2011.10.002.

9. Leuner C, Dressman J. Improving drug solubility for oral delivery using solid dispersions. Eur J Pharm Biopharm. 2000;50(1):47-60. doi: 10.1016/s09396411(00)00076-x, PMID 10840192.

10. Six K, Verreck G, Peeters J, Brewster M, Van Den Mooter G. Increased physical stability and improved dissolution properties of itraconazole, a Class II drug, by solid dispersions that combine fast- and slow-dissolving polymers. J Pharm Sci. 2004;93(1):124-31. doi: 10.1002/jps.10522, PMID 14648642.

11. Husseiny RA, Abu Lila AS, Abdallah MH, El-ghamry HA. Fast disintegrating tablet of valsartan for the treatment of pediatric hypertension: in vitro and in vivo evaluation. J Drug Deliv Sci Technol. 2018:43:194-200. doi: 10.1016/j. jddst.2017.10.014.

12. Shamma RN, Basha M. Soluplus $\AA$ : A novel polymeric solubilizer for optimization of carvedilol solid dispersions: formulation design and effect of method of preparation. Powder Technol. 2013;237:406-14. doi: 10.1016/j. powtec.2012.12.038.

13. Kini A, Patel SB. Phase behavior, intermolecular interaction, and solid state characterization of amorphous solid dispersion of febuxostat. Pharm Dev Technol. 2017;22(1):45-57. doi: 10.3109/10837450.2016.1138130, PMID 26853838.

14. Khan AW, Kotta S, Ansari SH, Sharma RK, Ali J. Enhanced dissolution and bioavailability of grapefruit flavonoid naringenin by solid dispersion utilizing fourth generation carrier. Drug Dev Ind Pharm. 2015;41(5):772-9. doi: 10.3109/03639045.2014.902466, PMID 24669978.

15. Linn M, Collnot EM, Djuric D, Hempel K, Fabian E, Kolter K, Lehr CM. Soluplus ${ }^{\circledR}$ as an effective absorption enhancer of poorly soluble drugs in vitro and in vivo. Eur J Pharm Sci. 2012;45(3):336-43. doi: 10.1016/j. ejps.2011.11.025, PMID 22172603.

16. Liu C, Liu Z, Chen Y, Chen Z, Chen H, Pui Y, Qian F. Oral bioavailability enhancement of $\beta$-lapachone, a poorly soluble fast crystallizer, by cocrystal, amorphous solid dispersion, and crystalline solid dispersion. Eur J Pharm Biopharm. 2018;124:73-81. doi: 10.1016/j.ejpb.2017.12.016, PMID 29305142.

17. Tawfeek HM, Abdellatif AAH, Dennison TJ, Mohammed AR, Sadiq Y, Saleem IY. Colonic delivery of indometacin loaded PGA-co-PDL microparticles coated with Eudragit L100-55 from fast disintegrating tablets. Int J Pharm. 2017;531(1):80-9. doi: 10.1016/j.jpharm.2017.08.069, PMID 28818458.

18. Pabari RM, Ramtoola Z. Application of face centred central composite design to optimise compression force and tablet diameter for the formulation of mechanically strong and fast disintegrating orodispersible tablets. Int $\mathrm{J}$ Pharm. 2012;430(1-2):18-25. doi: 10.1016/j.jppharm.2012.03.021, PMID 22465631.

19. Solaiman A, Suliman AS, Shinde S, Naz S, Elkordy AA. Application of general multilevel factorial design with formulation of fast disintegrating tablets containing croscaremellose sodium and Disintequick MCC-25. Int J Pharm. 2016;501(1-2):87-95. doi: 10.1016/j.jpharm.2016.01.065, PMID 26827922.

20. Umapathi P, Ayyappan J, Quine S. Development and validation of a dissolution test method for artemether and lumefantrine in tablets. Trop J Pharm Res. 2011;10(5):643-53. doi: 10.4314/tjpr.v10i5.14.

21. Kim DS, Choi JS, Kim DW, Kim KS, Seo YG, Cho KH, Kim JO, Yong CS, Youn YS, Lim SJ, Jin SG, Choi HG. Comparison of solvent-wetted and kneaded L-Sulpiride-Loaded solid dispersions: powder characterization and in vivo evaluation. Int J Pharm. 2016;511(1):351-8. doi: 10.1016/j. ijpharm.2016.07.006, PMID 27397868.

22. Khatri P, Shah MK, Patel N, Jain S, Vora N, Lin S. Preparation and characterization of pyrimethamine solid dispersions and an evaluation of the physical nature of pyrimethamine in solid dispersions. J Drug Deliv Sci Technol. 2018;45:110-23. doi: 10.1016/j.jddst.2018.03.012.

23. Fule RA, Meer TS, Sav AR, Amin PD. Artemether-Soluplus Hot-Melt Extrudate Solid Dispersion Systems for Solubility and Dissolution Rate Enhancement with Amorphous State Characteristics. J Pharm (Cairo). 2013;2013:151432. doi: 10.1155/2013/151432. PMID 26555968.

24. Fule R, Meer T, Sav A, Amin P. Solubility and dissolution rate enhancement of lumefantrine using hot melt extrusion technology with physicochemical characterisation. J Pharm Investig. 2013;43(4):305-21. doi: 10.1007/s40005013-0078-z.

25. Basha M, Salama A, Noshi SH. Soluplus $®$ based solid dispersion as fast disintegrating tablets: a combined experimental approach for enhancing the dissolution and antiulcer efficacy of famotidine. Drug Dev Ind Pharm. 2020;46(2):253-63. doi: 10.1080/03639045.2020.1716376, PMID 31937139.

26. Singh S, Srivastava RK, Srivastava M, Puri SK, Srivastava K. In-vitro culture of Plasmodium falciparum: utility of modified (RPNI) medium for drug-sensitivity studies using SYBR Green I assay. Exp Parasitol. 2011;127(1):318-21. doi: 10.1016/j.exppara.2010.08.007, PMID 20727351.

27. Sharma M, Chauhan K, Chauhan SS, Kumar A, Singh SV, Saxena JK, Agarwal P, Srivastava K, Raja Kumar S, Puri SK, Shah P, Siddiqi MI, Chauhan PMS. Synthesis of hybrid 4-anilinoquinoline triazines as potent antimalarial agents, their in silico modeling and bioevaluation as Plasmodium falciparum transketolase and $\beta$-hematin inhibitors. Med Chem Commun. 2012;3(1):71-9. doi: 10.1039/C1MD00188D.

28. Fule R, Dhamecha D, Maniruzzaman M, Khale A, Amin P. Development of hot melt co-formulated antimalarial solid dispersion system in fixed dose form (ARLUMELT): evaluating amorphous state and in vivo performance. Int J Pharm. 2015;496(1):137-56. doi: 10.1016/j.ijpharm.2015.09.069, PMID 26471056.

29. Shakeel K, Raisuddin S, Ali S, Imam SS, Rahman MA, Jain GK, Ahmad FJ. Development and in vitrolin vivo evaluation of artemether and lumefantrine co-loaded nanoliposomes for parenteral delivery. J Liposome Res. 2019;29(1):35-43. doi: 10.1080/08982104.2017.1410173, PMID 29179636.

30. Maulvi FA, Dalwadi SJ, Thakkar VT, Soni TG, Gohel MC, Gandhi TR. Improvement of dissolution rate of aceclofenac by solid dispersion technique. Powder Technol. 2011;207(1-3):47-54. doi: 10.1016/j.powtec.2010.10.009.

31. Pandit V, Pai RS, Devi K, Suresh S. In vitro-in vivo evaluation of fastdissolving tablets containing solid dispersion of pioglitazone hydrochloride. J Adv Pharm Technol Res. 2012;3(3):160-70. doi: 10.4103/2231-4040.101008, PMID 23057002.

32. Muñoz H, Castan H, Clares B, Ruiz MA. Obtaining fast dissolving disintegrating tablets with different doses of melatonin. Int $\mathrm{J}$ Pharm. 2014;467(1-2):84-9. doi: 10.1016/j.jpharm.2014.03.054, PMID 24699354.

33. Mizumoto T, Masuda Y, Yamamoto T, Yonemochi E, Terada K. Formulation design of a novel fast-disintegrating tablet. Int J Pharm. 2005;306(1-2):83-90. doi: 10.1016/j.jpharm.2005.09.009, PMID 16257154.

34. Salama AH, Basha M, El Awdan S. Experimentally designed lyophilized dry emulsion tablets for enhancing the antihyperlipidemic activity of atorvastatin calcium: preparation, in-vitro evaluation and in-vivo assessment. Eur J Pharm Sci. 2018;112:52-62. doi: 10.1016/j.ejps.2017.11.003, PMID 29117504. 
35. Türkmen Ö, Ay Şenyiğit Z, Baloğlu E. Formulation and evaluation of fexofenadine hydrochloride orally disintegrating tablets for pediatric use. $J$ Drug Deliv Sci Technol. 2018;43:201-10. doi: 10.1016/j.jddst.2017.10.008.

36. Jacob B, Bisht LK, Chandy V. Ludiflash. A novel excipient for patient friendly dosage form. STM J. 2018;7(2):5-7.
37. Heinz $\mathrm{R}$, Wolf $\mathrm{H}$, Schuchmann $\mathrm{H}$, End $\mathrm{L}$, Kolter $\mathrm{K}$. Formulation and development of tablets based on Ludipress and scale-up from laboratory to production scale. Drug Dev Ind Pharm. 2000;26(5):513-21. doi: 10.1081/ddc100101262, PMID 10789063.

\section{PICTORIAL ABSTRACT}

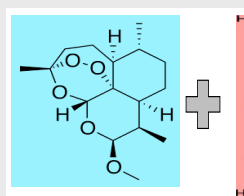

Artemether
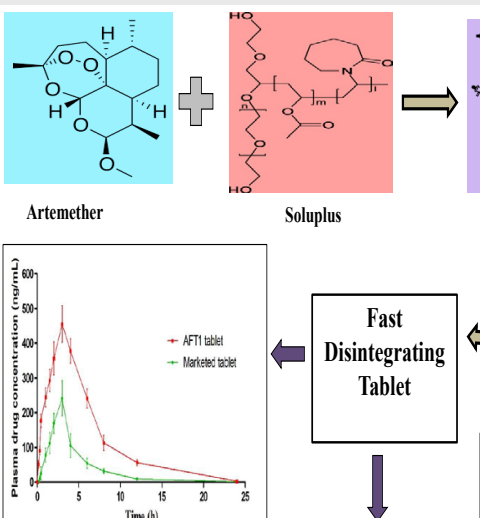

Solupl

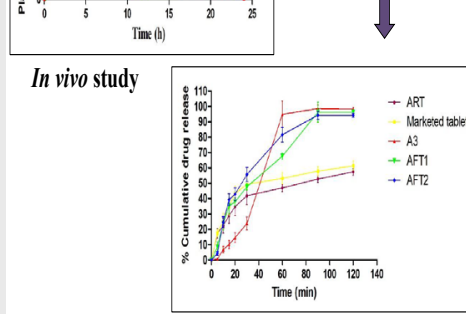

In vitro study

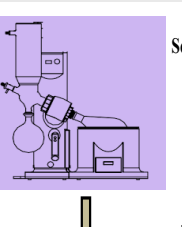

Solvent evaporation using Rotary evaporator

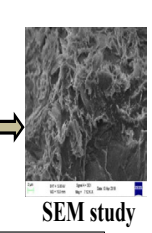

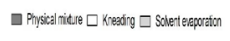

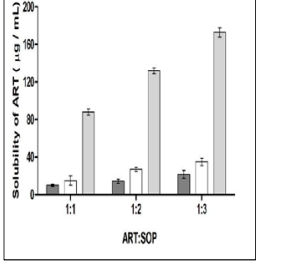

Solubility study

Solubility study

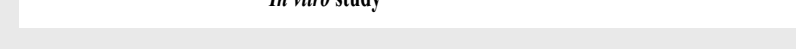

\section{SUMMARY}

The Artemether is having poor aqueous solubility and is frequently used in the treatment of malarial therapy. Solid dispersion was formulated using Soluplus by rotary evaporation technique and then the formed solid dispersion was incorporated in a suitable dosage form such as a fast disintegrating tablet. The characterization of the solid dispersion was performed using FTIR, DSC, XRD and SEM which showed conversion from crystalline to an amorphous form of Artemether. The phase solubility study showed higher efficacy with Soluplus. Thus, solid dispersion of the drug was prepared using Soluplus. The different ratios were tried and saturation solubility study was performed for all three ratios which revealed that the $1: 3$ ratio had higher aqueous solubility. The dissolution studies showed an improved dissolution rate with more than $90 \%$ of drug release. The in-vitro antimalarial screening was performed using Plasmodium falciparum 3D7 cell line assay which showed increased efficacy of the formulated solid dispersion. The in vitro cytotoxicity study was carried out using Vero cell line which depicted the safety of the formulated solid dispersion. The in-vivo pharmacokinetic study showed increased bioavailability of the Artemether when formulated in solid dispersion.

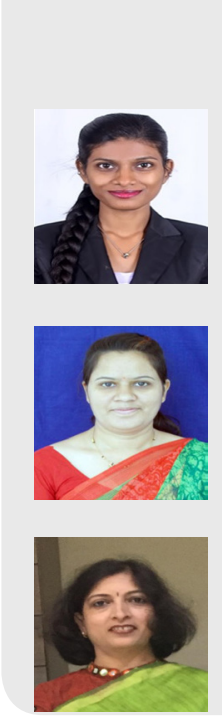

About Authors

Pranita S. Kanojiya: She is a Ph.D. research scholar at the Department of Pharmaceutical Sciences, Rashtrasant Tukadoji Maharaj Nagpur University, Nagpur.

Yogita M. Charde: She is currently working as an Assistant Professor at Sai Nath College of Pharmacy, Nagpur.

Dr. Rita N. Wadetwar: She is currently working as an Assistant Professor at the Department of Pharmaceutical Sciences, Rashtrasant Tukadoji Maharaj Nagpur University, Nagpur.

Cite this article: Kanojiya PS, Charde YM, Wadetwar RN. Solid Dispersion of Artemether in Fast Disintegrating Tablet to Enhance Dissolution Rate and Oral Bioavailability. Indian J of Pharmaceutical Education and Research. $2022 ; 56(1): 153-65$. 